\title{
Trends in clinical, operative, and pathologic characteristics of surgically treated renal mass in a Korean center: A surgical series from 1988 through 2015
}

\author{
Ho Won Kang ${ }^{1, *}$, Sung Pil Seo ${ }^{1, *}$, Won Tae Kim ${ }^{1}$, Seok Joong Yun ${ }^{1}$, Sang-Cheol Lee ${ }^{1}$, Wun-Jae Kim ${ }^{1}$, Eu Chang Hwang ${ }^{2}$, \\ Seok Ho Kang ${ }^{3}$, Sung-Hoo Hong ${ }^{4}$, Jinsoo Chung ${ }^{5}$, Tae Gyun Kwon ${ }^{6}$, Hyeon Hoe Kim ${ }^{7}$, Cheol Kwak', Seok-Soo Byun ${ }^{8}$, \\ Yong-June Kim ${ }^{1}$; KORCC (KOrean Renal Cell Carcinoma) Group \\ 'Department of Urology, Chungbuk National University Hospital, Chungbuk National University College of Medicine, Cheongju, ${ }^{2}$ Department of Urology, Chonnam \\ National University Hwasun Hospital, Hwasun, ${ }^{3}$ Department of Urology, Korea University School of Medicine, Seoul, ${ }^{4}$ Department of Urology, College of Medicine, \\ The Catholic University of Korea, Seoul, ${ }^{5}$ Department of Urology, National Cancer Center, Goyang, ${ }^{6}$ Department of Urology, Kyungpook National University College of \\ Medicine, Daegu, ${ }^{7}$ Department of Urology, Seoul National University College of Medicine, Seoul, ${ }^{8}$ Department of Urology, Seoul National University Bundang Hospital, \\ Seongnam, Korea
}

Purpose: To analyze trends over a period of 28 years in the clinical, operative, and pathologic characteristics of patients with a renal mass who underwent surgical resection in Korea.

Materials and Methods: Consecutive patients $(n=6,231)$ with a renal mass who underwent surgical resection at eight Korean institutions between 1988 and 2015 were reviewed. Patients were assigned to one of three groups according to the date of surgery: group 1, 1988-1999; group 2, 2000-2009; and group 3, 2010-2015.

Results: Age at the time of surgery, body mass index, smoking status, incidence of diabetes and hypertension, and the number of incidentally identified renal masses increased significantly over time. The proportion of patients undergoing partial nephrectomy (PN) or minimally invasive surgery (MIS) increased sharply during the last two time periods. From 2010, the rate of robot-assisted nephrectomy rose sharply, occurring in $37.8 \%$ of MIS cases. Benign pathology was identified in $1.8 \%$ and $5.2 \%$ of cases in the middle and last periods, respectively; angiomyolipoma was the most common pathology. In later years, tumors were more often localized, although tumor grade increased. Sub-group analysis of small renal masses $\leq 4 \mathrm{~cm}$ revealed similar trends in operative and pathologic characteristics over time.

Conclusions: Between 1988 and 2015, there was a substantial change in the clinical, operative, and histological characteristics of patients who underwent resection of a renal mass in Korea. The most notable changes were stage migration towards localized disease and widespread use of PN and MIS.

Keywords: Carcinoma, renal cell; Minimally invasive surgical procedures; Nephrectomy; Pathology, surgical

This is an Open Access article distributed under the terms of the Creative Commons Attribution Non-Commercial License (http://creativecommons.org/licenses/by-nc/4.0) which permits unrestricted non-commercial use, distribution, and reproduction in any medium, provided the original work is properly cited.

Received: 31 January, $2019 \cdot$ Accepted: 19 March, 2019

Corresponding Author: Yong-June Kim

Department of Urology, Chungbuk National University College of Medicine, 1 Chungdae-ro, Seowon-gu, Cheongju 28644, Korea

TEL: +82-43-269-6134, FAX: +82-43-269-6143, E-mail: urokyj@cbnu.ac.kr

ORCID: https://orcid.org/0000-0001-7638-7174

*These authors contributed equally to this study and should be considered co-first authors. 


\section{INTRODUCTION}

As in other developed countries, the incidence of renal tumors in Korea has increased during past decades [1]. For example, in the United States approximately 51,190 new cases of renal tumor were diagnosed in 2007 , a $128 \%$ increase compared with the 22,500 cases diagnosed in 1988 $[2,3]$. The reasons for this steady increase in diagnosis are multifactorial, but may be due in large part to increased use of imaging modalities that detect incidental tumors; thus renal cell carcinoma (RCC) is now diagnosed earlier, often at the localized stage [3]. As a result, partial nephrectomy (PN) for treatment of localized kidney tumors has been replaced by radical nephrectomy (RN) [4]. Moreover, technological advances and increased surgical expertise have facilitated the use of minimally invasive surgery (MIS) techniques to treat clinically localized RCC [5]. While open PN is the "traditional" standard, the last decade has seen significant advances in laparoscopic PN [6]. The laparoscopic nephronsparing procedure achieves results that are equivalent (oncologically speaking) to those of open PN, but with the advantages of reduced intraoperative blood loss and a shorter hospital stay [7,8]. More recently, robot-assisted $\mathrm{PN}$ is gaining popularity in the field of nephron-sparing surgery, given the unique features offered by the robotic platform including motion scaling, enhanced magnification, 3-dimensional stereoscopic vision, and improved instrument dexterity [9]. The unique technology underlying the robotic platform has allowed minimally invasive treatment of larger and anatomically more complex renal tumors [10]. The increasing incidence of small renal masses may also have resulted in the stage migration in renal tumors. More than $70 \%$ of renal tumors are detected incidentally, and these tumors are smaller than tumors detected after symptoms become apparent [3,11]. More importantly, a significant proportion of incidentally identified renal masses removed due to suspected malignancy ultimately prove to be benign [12].

It is assumed that the clinical, operative, and pathological characteristics of Korean kidney tumors has changed in a manner similar to that noted in other developed countries; however, contemporary data are lacking. Understanding these chronological trends is important if we are to develop appropriate public-health strategies for patients diagnosed with a renal tumor. The aim of the present multi-institutional study was to perform a comprehensive assessment of trends in clinical, operative, and pathologic characteristics of a large cohort of patients with renal tumors, and of a sub-group of patients with a small renal mass ( $\leq 4 \mathrm{~cm}$ ), between 1988 and 2015. We also discuss the distinct characteristics of Korean patients compared with those of patients in previous international studies.

\section{MATERIALS AND METHODS}

\section{Study population}

The study was approved by the relevant Institutional Review Boards at the eight participating centers. Informed consent was waived by the board. Data were collected retrospectively from 7,047 patients who underwent $\mathrm{RN}$ or PN for presumed RCC at one of eight Korean institutions from January 1988 through December 2015. The database contained patient clinicopathologic characteristics, including age at diagnosis, sex, body mass index (BMI), comorbidities (diabetes and hypertension), Eastern Cooperative Oncology Group (ECOG) performance status (PS), surgical method (RN or PN), surgical approach (open vs. MIS [and type of MIS]), clinical tumor characteristics (radiologic tumor size, tumor location, cTNM stage), pathological characteristics (histologic tumor size, pTN stage, Fuhrman nuclear grade, histologic subtype, lymphovascular invasion, and surgical margin status), disease recurrence and site of recurrence (local or metastatic), and information about death and cause of death. Private information (such as resident registration numbers and hospital ID numbers) was excluded to protect patient confidentiality [1,13]. The requirement for enrollment was complete information about the date of surgery and pathological characteristics of the tumor (benign vs. malignancy and RCC subtype). Consequently, 6,231 consecutive patients with renal mass who underwent surgical resection were included in the final analysis.

\section{Surgical protocols and pathologic evaluation}

The surgical procedures included open approaches, pure laparoscopic approaches, hand-assisted laparoscopic surgery (HALS), robot-assisted surgery, and laparoendoscopic singlesite surgery. The surgical modality and approach were decided by each surgeon in accordance with the clinical situation. All surgery was performed by skilled surgeons using standard methods. Inclusion of eight separate academic centers means that surgical techniques varied widely. All surgical specimens were processed according to standard pathologic procedures at each individual institution [1]. Pathological staging was based on the 7th edition of the American Joint Committee on Cancer classification system and histological differentiation was graded according to the Fuhrman nuclear grading system [14,15]. Perioperative morbidity was classified according to the Clavien-Dindo 
classification of surgical complications [16].

\section{Statistical analysis}

Patients were categorized into three groups according to date of surgery: group 1, 1988-1999; group 2, 2000-2009; and group 3, 2010-2015. Clinical, operative, and pathological parameters during each time period were compared using the chi-squared test (categorical variables) or ANOVA (continuous variables). Differences were considered significant at $\mathrm{p}<0.05$, and all reported $p$-values were twosided. Statistical analyses were performed using IBM SPSS Statistics 24.0 sof tware (IBM Co., Armonk, NY, USA).

\section{RESULTS}

\section{Trends in the clinical features of patients treated surgically between 1988 and 2015 to remove a renal mass}

A total of 382 (group 1, 1988-1999), 2991 (group 2, 20002009), and 2,858 (group 3, 2010-2015) patients with RCC treated surgically at one of the eight centers were analyzed. Several clinical factors were compared among patients from each period (Table 1). Age at the time of surgery, BMI, smoking status, incidence of diabetes and hypertension, and an incidentally identified renal mass increased significantly

Table 1. Trends in the clinical characteristics of patients with surgically treated renal mass

\begin{tabular}{|c|c|c|c|c|}
\hline \multirow{2}{*}{ Variable } & \multicolumn{3}{|c|}{ Date of surgery } & \multirow{2}{*}{ p-value } \\
\hline & Group 1 (1988-1999) & Group 2 (2000-2009) & Group 3 (2010-2015) & \\
\hline Total patients & 382 & 2,991 & 2,858 & \\
\hline Age $(y)$ & $52.7 \pm 11.4$ & $55.5 \pm 12.7$ & $56.0 \pm 13.4$ & $<0.001^{\mathrm{a}}$ \\
\hline Age categories (y) & & & & $<0.001^{b}$ \\
\hline$<34$ & $22(5.8)$ & $153(5.1)$ & $153(5.4)$ & \\
\hline $35-64$ & $301(78.8)$ & $2,030(67.9)$ & $1,905(66.7)$ & \\
\hline$\geq 65$ & $59(15.4)$ & $808(27.0)$ & $800(28.0)$ & \\
\hline Body mass index $\left(\mathrm{kg} / \mathrm{m}^{2}\right)$ & $23.9 \pm 3.2$ & $24.2 \pm 3.3$ & $24.6 \pm 3.4$ & $<0.001^{\mathrm{a}}$ \\
\hline Sex & & & & $0.927^{b}$ \\
\hline Male & $271(70.9)$ & $2,093(70.0)$ & $2,003(70.1)$ & \\
\hline Female & $111(29.1)$ & $898(30.0)$ & $855(29.9)$ & \\
\hline Smoking & & & & $<0.001^{b}$ \\
\hline Never smoker & $17 / 32(53.1)$ & $1,241 / 1,796(69.1)$ & $1,869 / 2,677(69.8)$ & \\
\hline Ex-smoker & $3 / 32(9.4)$ & $142 / 1,796(7.9)$ & $373 / 2,677(13.9)$ & \\
\hline Current & $12 / 32(37.5)$ & $413 / 1,796(23.0)$ & $435 / 2,677(16.2)$ & \\
\hline Not available & 350 & 1,195 & 181 & \\
\hline Diabetes mellitus & & & & $<0.001^{b}$ \\
\hline Yes & $28 / 368(7.6)$ & $376 / 2,713(13.9)$ & $444 / 2,842(15.6)$ & \\
\hline No & $340 / 368(92.4)$ & $2,337 / 2,713(86.1)$ & 2,398/2,842 (84.4) & \\
\hline Not available & 14 & 278 & 16 & \\
\hline Hypertension & & & & $<0.001^{\mathrm{b}}$ \\
\hline Yes & $70 / 368(19.0)$ & $953 / 2,705(35.2)$ & $1,213 / 2,806(43.2)$ & \\
\hline No & $298 / 368(81.0)$ & $1,752 / 2,705(64.8)$ & $1,593 / 2,806(56.8)$ & \\
\hline Not available & 14 & 286 & 52 & \\
\hline ECOG-PS scale & & & & $<0.001^{b}$ \\
\hline $0-1$ & $61 / 62(98.4)$ & $2,069 / 2,545(81.3)$ & 1,998/2,173 (91.9) & \\
\hline 2 & $0 / 62(0.0)$ & $422 / 2,545(16.6)$ & $147 / 2,173(6.8)$ & \\
\hline$\geq 3$ & $1 / 62(1.6)$ & $54 / 2,545(2.1)$ & $28 / 2,173(1.3)$ & \\
\hline Not available & 320 & 446 & 685 & \\
\hline Symptoms at diagnosis & & & & $<0.001^{\mathrm{b}}$ \\
\hline Incidental & $235(61.5)$ & $2,205 / 2,981(74.0)$ & $2,252 / 2,781(81.0)$ & \\
\hline Symptomatic & $146(38.2)$ & $776 / 2,981(26.0)$ & $529 / 2,781(19.0)$ & \\
\hline Not available & 0 & 10 & 77 & \\
\hline
\end{tabular}

Values are presented as number only, mean \pm standard deviation, or number (\%).

ECOG-PS, Eastern Cooperative Oncology Group performance status.

${ }^{\mathrm{a}}$ :ANOVA, ${ }^{\mathrm{b}}$ :chi-squared test. 
with time (each $\mathrm{p}<0.001$ ). The proportion of patients diagnosed at a young age $(<34$ years) was similar over time; however, the number aged 65 years or older increased from $15.4 \%$ in group 1 to $>27.0 \%$ in groups 2 and 3 ( $p<0.001)$. Over the last two time periods, the proportion of patients with ECOG-PS 2 or 3 increased significantly $(p<0.001)$. The male to female ratio did not show a significant change over time $(p=0.927)$ (Table 1$)$.

\section{Trends in operative procedures used for pa- tients with a renal mass between 1988 and 2015}

Use of PN increased from one time group to the next throughout the study period (3.7\%, $27.0 \%$, and $54.0 \%$ in groups 1, 2, and 3, respectively; p<0.001) (Fig. 1A). The proportion of patients undergoing MIS increased significantly from the first to the last time period, both in the total cohort (Fig. 1B) and in the PN (Fig. 1C) and RN (Fig. 1D) cohorts (each $\mathrm{p}<0.001$ ). Regarding the type of MIS, utilization of HALS declined significantly throughout the study period, while that of laparoscopic nephrectomy remained surgery be kept stable after showing a sharp increase from 2003 (Fig. 1E) $(p<0.001)$. Increased utilization of robot-assisted laparoscopic nephrectomy was evident from late 2000, particularly for PN (Fig. 2). Perioperative complications $\geq$ grade 3 tended to be higher in the late group, although this was not statistically significant $(\mathrm{p}=0.665)$ (Table 2$)$.

\section{Trends in the histologic characteristics of renal masses resected between 1988 and 2015}

Of the 6,231 resected renal masses, 53 (1.8\%) and 149 (5.2\%) of those in groups 2 and 3 had benign pathologic findings ( $\mathrm{p}<0.001)$ (Fig. 3A). Of these, $15(28.3 \%)$ and $38(25.5 \%)$, respectively, did not undergo nephron-sparing surgery. Of the 202 benign lesions, 88 (43.6\%) were angiomyolipomas, 51 (25.2\%) were oncocytomas, 32 (15.8\%) were benign cyst lesions, and the remainder were miscellaneous benign entities. The incidence of benign cyst lesions increased significantly over the study period, whereas that of oncocytoma declined $(\mathrm{p}=0.027)$.

With respect to RCC pathology, clear cell RCC was the most common ( $>80 \%$ of cases). There was a significant
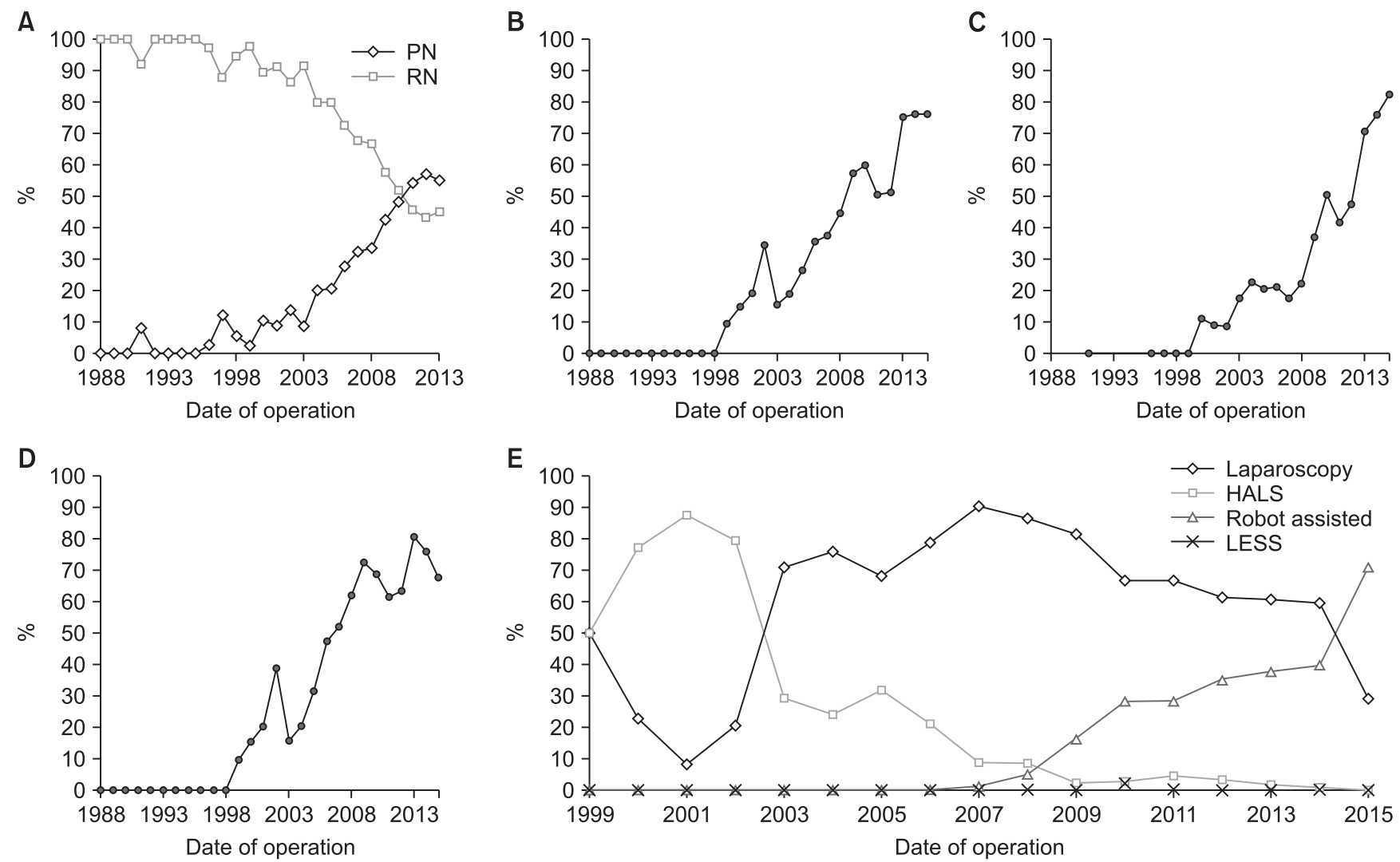

Fig. 1. Annual trends in the type of surgical procedure used for patients with a renal mass in Korea (between 1988 and 2015). (A) Percentage of partial nephrectomy (PN) cases relative to the total number of surgical cases. (B) Percentage of minimally invasive surgery (MIS) cases relative to the total number of surgical cases. (C) Percentage of MIS cases relative to the total number of surgical cases in patients who underwent PN. (D) Percentage of MIS cases relative to the total number of surgical cases in patients who underwent radical nephrectomy (RN). (E) Utilization of MIS techniques. HALS, hand-assisted laparoscopic surgery; LESS, laparo-endoscopic single-site surgery. 


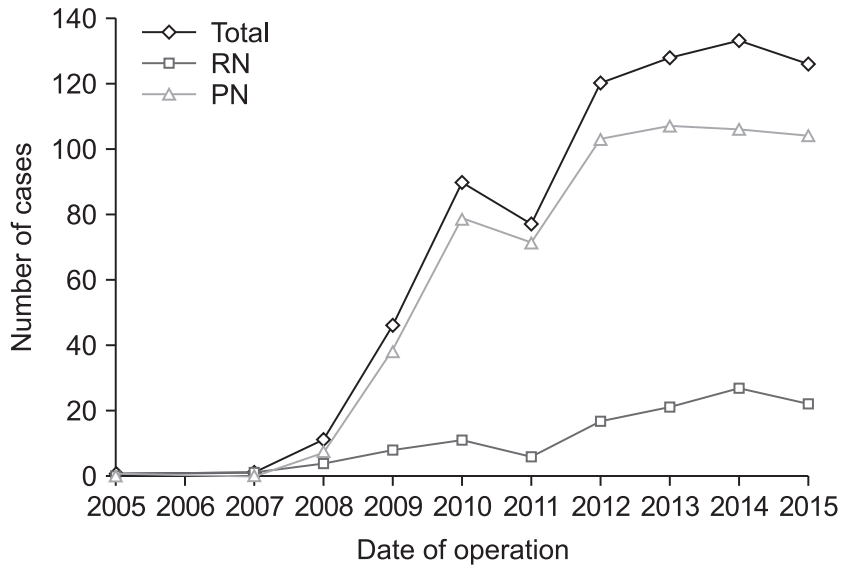

Fig. 2. Annual utilization of robot-assisted laparoscopic nephrectomy. Data show the number of patients per year managed using this technique. RN, radical nephrectomy; PN, partial nephrectomy. difference between the three groups in terms of the distribution of RCC subtype. Since 2000, the incidence of clear cell RCC decreased slightly, but that of chromophobe and miscellaneous malignant entities increased $(\mathrm{p}=0.015)$ (Fig. 3B). In later years, tumors were more often localized; the incidence of T1 tumors increased and that of metastatic tumors decreased, whereas that of T3 tumors remained stable $(\mathrm{p}<0.001)$ (Fig. 3C). Regarding tumor grade, the percentage of high-grade tumors increased in the middle and latest time periods $(\mathrm{p}<0.001)$ (Fig. 3D, Table 3).

\section{Trends in clinico-operative and pathologic characteristics of a sub-group of patients with a small renal mass $(\leq 4 \mathrm{~cm})$}

When patients were stratified according to tumor diameter $(\leq 4 \mathrm{~cm})$, we found that the proportion of patients with a small renal mass increased over time (35.6\%, $51.5 \%$,

Table 2. Trends in surgical procedure used to manage patients with a renal mass

\begin{tabular}{|c|c|c|c|c|}
\hline \multirow{2}{*}{ Variable } & \multicolumn{3}{|c|}{ Date of surgery } & \multirow{2}{*}{ p-value } \\
\hline & Group 1 (1988-1999) & Group 2 (2000-2009) & Group 3 (2010-2015) & \\
\hline Total patients & 382 & 2,991 & 2,858 & \\
\hline Operative methods & & & & $<0.001$ \\
\hline $\mathrm{RN}$ & $368(96.3)$ & $2,183(73.0)$ & $1,314(46.0)$ & \\
\hline PN & $14(3.7)$ & $808(27.0)$ & $1,544(54.0)$ & \\
\hline PN indication & & & & $<0.001$ \\
\hline Imperative & $0(0.0)$ & $77 / 806(9.6)$ & $43 / 1,536(2.8)$ & \\
\hline Elective & $14 / 14(100.0)$ & $729 / 806(90.4)$ & $1,493 / 1,536(97.2)$ & \\
\hline Not available & 0 & 2 & 8 & \\
\hline Surgical technique & & & & $<0.001$ \\
\hline Open & $371 / 379(97.9)$ & $1,734 / 2,805(61.8)$ & $1,026 / 2,809(36.5)$ & \\
\hline MIS & $8 / 379(2.1)$ & $1,071 / 2,805(38.2)$ & $1,783 / 2,809(63.5)$ & \\
\hline Not available & 3 & 186 & 49 & \\
\hline PN technique & & & & $<0.001$ \\
\hline Open & $14 / 14(100.0)$ & $580 / 775(74.8)$ & $635 / 1,531(41.5)$ & \\
\hline MIS & $0(0.0)$ & $195 / 775(25.2)$ & $896 / 1,531(58.5)$ & \\
\hline Not available & 0 & 33 & 13 & \\
\hline Type of MIS & & & & $<0.001$ \\
\hline Laparoscopic & $4 / 8(50.0)$ & $817 / 1,071(76.3)$ & $1,063 / 1,783(59.6)$ & \\
\hline HALS & $4 / 8(50.0)$ & $195 / 1,071(18.2)$ & $38 / 1,783(2.1)$ & \\
\hline Robot-assisted & $0(0.0)$ & $59 / 1,071(5.5)$ & $674 / 1,783(37.8)$ & \\
\hline LESS & $0(0.0)$ & $0(0.0)$ & $8 / 1,783(0.4)$ & \\
\hline Perioperative complication & & & & 0.665 \\
\hline Grade 1-2 & $30 / 38(78.9)$ & $185 / 261(70.9)$ & $164 / 241(68.0)$ & \\
\hline Grade 3-4 & $8 / 38(21.1)$ & $74 / 261(28.4)$ & $74 / 241(30.7)$ & \\
\hline Grade 5 & 0 & $2 / 261(0.8)$ & $3 / 241(1.2)$ & \\
\hline Not available & 344 & 2,730 & 2,617 & \\
\hline
\end{tabular}

Values are presented as number only or number (\%).

RN, radical nephrectomy; PN, partial nephrectomy; MIS, minimally invasive surgery; HALS, hand-assisted laparoscopic surgery; LESS, laparoendoscopic single-site surgery.

All p-values were calculated using the chi-squared test. 

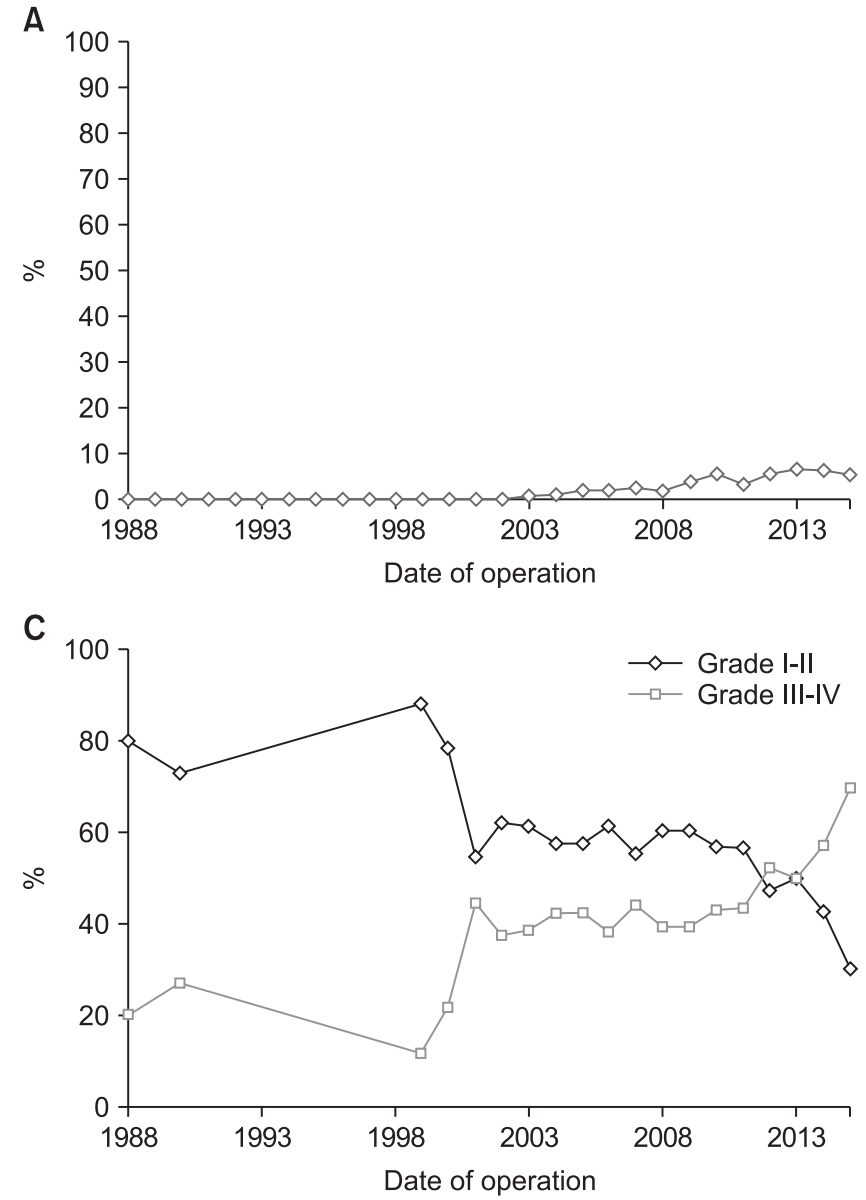
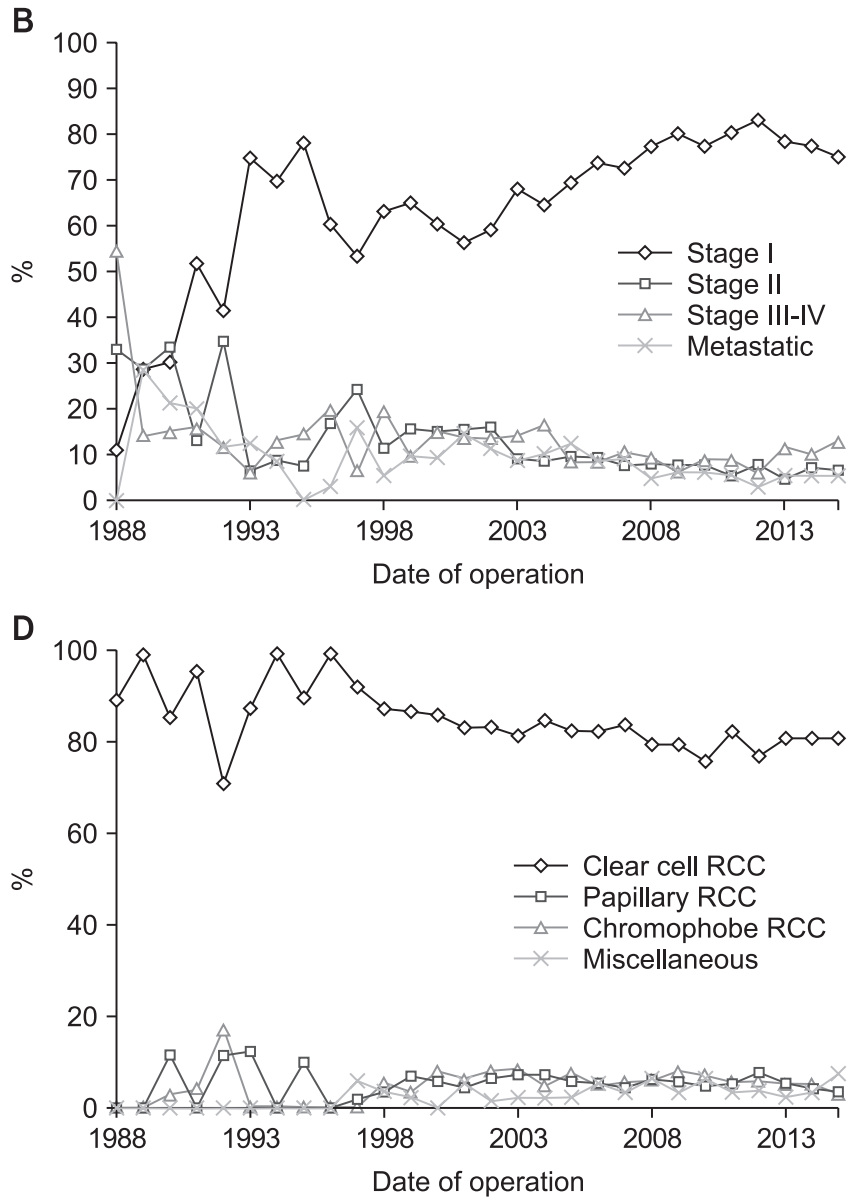

Fig. 3. Annual trends in pathologic variables of patients with a surgically treated renal mass between 1988 and 2015. (A) Incidence of benign pathology relative to total number of surgical cases. (B) Pathologic staging. (C) Fuhrman nuclear grading. (D) Histologic distribution of renal cell carcinoma (RCC) tumors.

and $60.5 \%$ in groups 1,2 , and 3 , respectively; $\mathrm{p}<0.001$ ) (Table 4). A similar trend in terms of increased utilization of $\mathrm{PN}$ and MIS over time was also evident in this sub-group. Utilization of robot-assisted laparoscopic PN was more common than that of laparoscopic PN during the last time period ( $p<0.001$ ). Regarding pathologic characteristics, $2.5 \%$ and $6.4 \%$ of cases in the second and last periods, respectively, showed benign pathology $(p<0.001)$. By contrast, there was no significant difference in the distribution of RCC subtype between the three time periods when patients were stratified according to a renal mass $\leq 4 \mathrm{~cm}(\mathrm{p}=0.054)$ (Table 4$)$.

\section{DISCUSSION}

The present study examined trends over time in the clinical, operative, and pathologic characteristics of renal masses resected from Korean patients over 28 years. Stage migration towards small RCC and widespread use of PN and MIS were the most noticeable changes. Adoption of robotic surgery for both $\mathrm{PN}$ and $\mathrm{RN}$ rose sharply from the second period onward. Comparative effectiveness studies and new health technology assessments are therefore needed with respect to robot-assisted nephrectomy. The number of preoperatively misclassified benign renal masses increased markedly during the later time periods, resulting in about one out of four patients losing the entire kidney despite having a benign diagnosis; this paralleled the increase in the number of surgically resected small RCCs. Therefore, nephron-sparing surgery should be the preferred treatment in all cases of small renal mass.

The results of the international GLOBOCAN 2012 study report a greater worldwide increase in the incidence of kidney cancer than the GLOBOCAN 2008 and 2002 studies $[17,18]$. In Korea, the age-standardized incidence rates and annual percentage changes in the incidence of RCC during 1999-2012 were estimated at 4.4 per 100,000 persons and 5.80\%, respectively [19]. Here, we found that the number of surgeries to resect a renal mass increased sharply during each time period. King et al. [17] examined the National Program of Cancer Registries and Surveillance, 
Table 3. Trends in pathologic variables of patients with a surgically treated renal mass

\begin{tabular}{|c|c|c|c|c|}
\hline \multirow{2}{*}{ Variable } & \multicolumn{3}{|c|}{ Date of surgery } & \multirow{2}{*}{ p-value } \\
\hline & Group 1 (1988-1999) & Group 2 (2000-2009) & Group 3 (2010-2015) & \\
\hline Total patients & 382 & 2,991 & 2,858 & \\
\hline Renal mass laterality & & & & $0.456^{\mathrm{b}}$ \\
\hline Right & $201(52.6)$ & $1,494(49.9)$ & $1,387(48.5)$ & \\
\hline Left & $180(47.1)$ & $1,479(49.4)$ & $1,451(50.8)$ & \\
\hline Both & $1(0.3)$ & $18(0.6)$ & $20(0.7)$ & \\
\hline Pathology & & & & $<0.001^{\mathrm{b}}$ \\
\hline Benign & $0(0.0)$ & $53(1.8)$ & $149(5.2)$ & \\
\hline RN & $0(0.0)$ & $15(28.3)$ & $38(25.5)$ & $0.691^{\mathrm{b}}$ \\
\hline Malignant & $382(100.0)$ & $2,938(98.2)$ & $2,709(94.8)$ & \\
\hline RN & $368(96.3)$ & $2,168(73.8)$ & $1,276(47.1)$ & $<0.001^{\mathrm{b}}$ \\
\hline Benign histology & & & & $0.027^{b}$ \\
\hline AML & $0(0.0)$ & $22 / 53(41.5)$ & $66 / 149(44.3)$ & \\
\hline Oncocytoma & $0(0.0)$ & $20 / 53(37.7)$ & $31 / 149(20.8)$ & \\
\hline Benign cyst & $0(0.0)$ & $3 / 53(5.7)$ & $29 / 149(19.5)$ & \\
\hline Miscellaneous & $0(0.0)$ & $8 / 53(15.1)$ & $23 / 149(15.4)$ & \\
\hline RCC subtype & & & & $<0.015^{b}$ \\
\hline Clear cell & $343(89.8)$ & $2,450 / 2,938(83.4)$ & $2,262 / 2,709(83.5)$ & \\
\hline Papillary & $20(5.2)$ & $175 / 2,938(6.0)$ & $159 / 2,709(5.9)$ & \\
\hline Chromophobe & $11(2.9)$ & $198 / 2,938(6.7)$ & $164 / 2,709(6.1)$ & \\
\hline Miscellaneous & $8(2.1)$ & $115 / 2,938(3.9)$ & $124 / 2,709(4.6)$ & \\
\hline Renal mass size (mm) & $61.1 \pm 34.1$ & $50.4 \pm 45.6$ & $42.6 \pm 34.2$ & $<0.001^{\mathrm{a}}$ \\
\hline TNM stage & & & & $<0.001^{\mathrm{b}}$ \\
\hline pT1 & $219(57.3)$ & $2,095 / 2,938(71.3)$ & $2,134 / 2,709(78.8)$ & \\
\hline pT2 & $67(17.5)$ & $278 / 2,938(9.5)$ & $170 / 2,709(6.3)$ & \\
\hline pT3-4 & $55(14.4)$ & $307 / 2,938(10.4)$ & $260 / 2,709(9.6)$ & \\
\hline Any $\mathrm{pT}, \geq \mathrm{pN} 1$, or $\mathrm{cM} 1$ & $41(10.7)$ & $258 / 2,938(8.8)$ & $145 / 2,709(5.4)$ & \\
\hline Fuhrman grade & & & & $<0.001^{\mathrm{b}}$ \\
\hline $1-2$ & $35 / 44(79.5)$ & $1,680 / 2,826(59.4)$ & $1,165 / 2,345(49.7)$ & \\
\hline $3-4$ & $9 / 44(20.5)$ & $1,146 / 2,826(40.6)$ & $1,180 / 2,345(50.3)$ & \\
\hline Not available & 338 & 112 & 364 & \\
\hline
\end{tabular}

Values are presented as number only, number (\%), or mean \pm standard deviation.

$\mathrm{RN}$, radical nephrectomy; AML, angiomyolipoma; RCC, renal cell carcinoma.

a:ANOVA, ${ }^{\text {b }}$ chi-squared test.

Epidemiology and End Results (SEER) data from 2001 to 2010 and found a continued increase in the incidence of RCC from 2001 to 2010, with the largest annual percentage change noted in young female adults and the number of localized and grade III tumors. Our results reveal similar trends in RCC in later years, i.e., towards a more localized stage and a higher grade. We did not observe a significant difference in incidence between sex. Another discrepant result of the present study compare to study by King et al. [17] was a significant increase in the proportion of those aged 65 years or older at the time of diagnosis, whereas the proportion of those aged under 34 years remained steady over time [11]. Another epidemiologic study based on the population-based United States Kidney Cancer Study from 2002 through 2007 showed an increase in small, asymptomatic RCC, in the prevalence of diabetes, and in the incidence of significant comorbidities [11]. Our data also show a similar trend throughout the study period, in which there was a significant increase in the proportion of patients with ECOG-PS of 2 or 3, as well as increased prevalence of diabetes and hypertension. The cohort examined in the present study was limited to patients who underwent surgery; therefore, this was not a nationwide populationbased epidemiological study. The data should be interpreted as an expansion of surgical indications for and widespread use of MIS in elderly patients with comorbidities. The shift in practice from open nephrectomy to MIS for management of RCC is demonstrated by numerous studies [20]. Golombos 
Table 4. Trends in clinical, operative, and pathologic variables of patients with a surgically treated small renal mass $(\leq 4 \mathrm{~cm})$

\begin{tabular}{|c|c|c|c|c|}
\hline \multirow{2}{*}{ Variable } & \multirow[b]{2}{*}{ Group 1 (1988-1999) } & \multicolumn{2}{|c|}{ Date of surgery } & \multirow{2}{*}{ p-valu } \\
\hline & & Group 2 (2000-2009) & Group 3 (2010-2015) & \\
\hline Total patients & $136 / 382(35.6)$ & $1,539 / 2,991(51.5)$ & $1,728 / 2,858(60.5)$ & $<0.001^{b}$ \\
\hline Age (y) & $51.6 \pm 11.4$ & $55.1 \pm 12.6$ & $55.6 \pm 12.9$ & $0.002^{\mathrm{a}}$ \\
\hline Symptoms at diagnosis & & & & $0.826^{\mathrm{b}}$ \\
\hline Incidental & $120(88.2)$ & $1,352 / 1,533(88.2)$ & $1,477 / 1,688(87.5)$ & \\
\hline Symptomatic & $16(11.8)$ & $181 / 1,533(11.8)$ & $211 / 1,688(12.5)$ & \\
\hline Not available & 0 & 6 & 40 & \\
\hline Operative methods & & & & $<0.001^{b}$ \\
\hline $\mathrm{RN}$ & $123(90.4)$ & $812(52.8)$ & $426(24.7)$ & \\
\hline PN & $13(9.6)$ & $727(47.2)$ & $1,302(75.3)$ & \\
\hline Surgical technique & & & & $<0.001^{b}$ \\
\hline Open & $130(95.6)$ & $859 / 1,464(58.7)$ & $592 / 1,701(34.8)$ & \\
\hline MIS & $6(4.4)$ & $605 / 1,464(41.3)$ & $1,109 / 1,701$ (65.2) & \\
\hline Not available & 0 & 75 & 27 & \\
\hline PN technique & & & & $<0.001^{b}$ \\
\hline Open & $13 / 13(100.0)$ & $519 / 696(74.6)$ & $503 / 1,289(39.0)$ & \\
\hline MIS & $0(0.0)$ & $177 / 696(25.4)$ & $786 / 1,289(61.0)$ & $<0.001^{b}$ \\
\hline Laparoscopic & $0(0.0)$ & $128 / 177(72.3)$ & $292 / 786(37.2)$ & \\
\hline HALS & $0(0.0)$ & $7 / 177(4.0)$ & $1 / 786(0.1)$ & \\
\hline Robot-assisted & $0(0.0)$ & $42 / 177(23.7)$ & 493/786 (62.7) & \\
\hline Not available & 0 & 31 & 13 & \\
\hline Pathology & & & & $<0.001^{b}$ \\
\hline Benign & $0(0.0)$ & $39(2.5)$ & $110(6.4)$ & \\
\hline Malignant & $136(100.0)$ & $1,500(97.5)$ & $1,618(93.6)$ & $0.054^{b}$ \\
\hline Clear cell & $127(93.4)$ & $1,264(84.3)$ & $1,357(83.9)$ & \\
\hline Papillary & $7(5.1)$ & $102(6.8)$ & $113(7.0)$ & \\
\hline Chromophobe & $2(1.5)$ & $91(6.1)$ & $90(5.6)$ & \\
\hline Miscellaneous & $0(0.0)$ & $43(2.9)$ & $58(3.6)$ & \\
\hline
\end{tabular}

Values are presented as number (\%), mean \pm standard deviation, or number only.

RN, radical nephrectomy; PN, partial nephrectomy; MIS, minimally invasive surgery; HALS, hand-assisted laparoscopic surgery.

${ }^{\mathrm{a}}:$ AVOVA, ${ }^{\mathrm{b}}$ :chi-squared test.

et al. [21] reported widespread adoption of minimally invasive approaches to RN across the United States. They examined the SEER and Medicare insurance program database and found that the use of MIS increased from 18.4\% in 2001-2004 to 43.5\% in 2009-2012 [21]. Banegas et al. [22] also reported a significant increase in the use of MIS for surgical management of patients with RCC in the United States. Similarly, our data from the total cohort and from the PN and $\mathrm{RN}$ cohorts indicate a significant increase over time in the use of MIS for treatment of renal masses. During the final period of the present study, MUS was used in $63.5 \%$ in total nephrectomy cases and in $58.5 \%$ in PN cases, which is slightly higher or comparable to data reported by a previous study [21,22]. Regarding the type of MIS, increased utilization of robot-assistance was evident from 2010, particularly for PN. Robot-assisted PN has potential advantages over laparoscopic PN as it combines nephron-sparing surgery with a minimally invasive approach. A surgical series of 14,260 patients who underwent $\mathrm{RN}$ or $\mathrm{PN}$ or renal ablation (data from the Maryland Health Services Cost Review Commission database) shows that use of robot-assisted laparoscopic PN increased from 2008 to 2011, attaining a $14 \%$ usage rate at university hospitals and a $10 \%$ rate at non-university hospitals [5]. Another Nationwide Inpatient Sample study reported that the relative annual increase in open, robotic, and laparoscopic PN was 7.9\%, 45.4\%, and 6.1\%, respectively, in 2010 [23]. Here, we found that use of robotassisted nephrectomy among patients who received MIS for treatment of renal mass increased from 5.5\% in 2000-2009 to $37.8 \%$ in $2010-2015$. Studies based on national registry data from the United States show that PN was relatively uncommon before 2002, representing less than $10 \%$ of overall nephrectomies; however, it increased annually from $16.8 \%$ in 2003 to $25.1 \%$ in 2008 [24]. Between 2000 and 2007, use of 
elective PN to treat tumors of $<4 \mathrm{~cm}$ at the Memorial SloanKettering Cancer Center (MSKCC) increased steadily from $69 \%$ in 2000 to $89 \%$ in 2007 ; similarly, use of elective PN to treat tumors measuring 4 to $7 \mathrm{~cm}$ increased from $20 \%$ in 2000 to $60 \%$ in 2007 [25]. The findings of the present study are consistent with a MSKCC experience, which showed an increase in the use of PN from 3.7\% in 1988-1999 to 54\% in 2010-2015. If limited to small renal mass less than $4 \mathrm{~cm}, \mathrm{PN}$ was used in 75.3\% of surgical cases in 2010-2015.

Another contemporary issue with respect to surgical treatment of a renal mass is the rate of benign histologic findings after surgery for presumed RCC [12]. Despite efforts to assess malignant potential, treatment planning remains uncertain because of the failure of current imaging and biopsy techniques to distinguish various types of RCC from benign pathologic entities [26]. Previous pooled analyses noted a frequency of benign tumors after partial or $\mathrm{RN}$ ranging from $7 \%$ to $33 \%$, with a median of $13.9 \%$ [27]. The prevalence of benign findings herein was $3 \%$, which is lower than that reported in previous reports from Korea and Western countries [26,27]. The most common benign lesion was angiomyolipoma, which is consistent with a previous Korean study; the most common lesion in Western countries is oncocytoma [26,27]. Although we rarely observed preoperatively misclassified benign renal masses, the incidence of benign pathologic entities is increasing alongside more frequent detection of small renal masses. Therefore, nephron-sparing surgery should be considered as the preferred treatment for small renal masses, considering that $25.5 \%$ of patients diagnosed with a benign tumor had the entire kidney removed.

Regarding RCC pathology, present study found a significant difference in the distribution of RCC subtype between the three time periods. Notably, since 2000, the incidence of clear cell RCC decreased slightly, but that of chromophobe and miscellaneous malignant entities increased. There are conflicting reports concerning the prognostic impact of histological subtype on oncologic outcomes in patients with surgically treated RCC [28-30]. While some studies have found a significant association between histological subtype with oncologic outcomes, other series did not identify this relationship [28-30]. Unfortunately, the lack of similar reports of chronological difference in RCC subtype makes it difficult to interpret our results. Further research is now needed to confirm our observations and to determine the prognostic influence of chronological difference in RCC subtype on oncologic outcomes in patients with surgically treated RCC.

This study has several limitations and strengths. Although we included a large number of patients in the data set, we were confined by the retrospective nature of the study, which may introduce sampling bias. The data set included only patients who had undergone surgery for a suspicious renal mass. We did not capture patients with advanced stage disease or aged patients with comorbidities who could be managed surgically. Therefore, the results are not generalizable to all Korean patients with RCC. In addition, the lack of a central pathology review may have introduced interobserver bias. However, despite these limitations the present study is the first nationwide multicenter study to provide insight into comprehensive trends underlying the clinical, operative, and pathologic characteristics of Korean patients with a renal mass.

\section{CONCLUSIONS}

Between 1988 and 2015, there was a pronounced change in surgical management and pathological variables in a large cohort of RCC patients in Korea. Stage migration towards localized disease and widespread use of PN and MIS were the most notable changes. The utilization of robot-assisted nephrectomy rose sharply during later years. Comparative effectiveness studies and new health technology assessments are warranted with respect to robot-assisted nephrectomy. The present data provide a comprehensive overview of contemporary trends in the clinical, operative, and pathological characteristics of Korean patients with RCC.

\section{CONFLICTS OF INTEREST}

The authors have nothing to disclose.

\section{ACKNOWLEDGMENTS}

This research was supported by the Basic Science Research Program through the National Research Foundation of Korea (NRF), funded by the Ministry of Education (2018R1D1A1B07043906).

\section{REFERENCES}

1. Byun SS, Hong SK, Lee S, Kook HR, Lee E, Kim HH, et al. The establishment of KORCC (Korean renal cell carcinoma) database. Investig Clin Urol 2016;57:50-7.

2. Stafford HS, Saltzstein SL, Shimasaki S, Sanders C, Downs TM, Sadler GR. Racial/ethnic and gender disparities in renal cell carcinoma incidence and survival. J Urol 2008;179:1704-8. 
3. Kane CJ, Mallin K, Ritchey J, Cooperberg MR, Carroll PR. Renal cell cancer stage migration: analysis of the National Cancer Data Base. Cancer 2008;113:78-83.

4. Mir MC, Derweesh I, Porpiglia F, Zargar H, Mottrie A, Autorino R. Partial nephrectomy versus radical nephrectomy for clinical T1b and T2 renal tumors: a systematic review and meta-analysis of comparative studies. Eur Urol 2017;71:606-17.

5. Patel HD, Mullins JK, Pierorazio PM, Jayram G, Cohen JE, Matlaga BR, et al. Trends in renal surgery: robotic technology is associated with increased use of partial nephrectomy. J Urol 2013;189:1229-35.

6. Weise ES, Winfield HN. Laparoscopic partial nephrectomy. J Endourol 2005;19:634-42.

7. Gill IS, Desai MM, Kaouk JH, Meraney AM, Murphy DP, Sung GT, et al. Laparoscopic partial nephrectomy for renal tumor: duplicating open surgical techniques. J Urol 2002;167:469-7; discussion 475-6.

8. Gill IS, Kavoussi LR, Lane BR, Blute ML, Babineau D, Colombo JR Jr, et al. Comparison of 1,800 laparoscopic and open partial nephrectomies for single renal tumors. J Urol 2007;178:416.

9. Benway BM, Bhayani SB, Rogers CG, Dulabon LM, Patel MN, Lipkin M, et al. Robot assisted partial nephrectomy versus laparoscopic partial nephrectomy for renal tumors: a multi-institutional analysis of perioperative outcomes. J Urol 2009;182:866-72.

10. Rogers CG, Singh A, Blatt AM, Linehan WM, Pinto PA. Robotic partial nephrectomy for complex renal tumors: surgical technique. Eur Urol 2008;53:514-21.

11. Miller DC, Ruterbusch J, Colt JS, Davis FG, Linehan WM, Chow WH, et al. Contemporary clinical epidemiology of renal cell carcinoma: insight from a population based case-control study. J Urol 2010;184:2254-8.

12. Johnson DC, Vukina J, Smith AB, Meyer AM, Wheeler SB, Kuo TM, et al. Preoperatively misclassified, surgically removed benign renal masses: a systematic review of surgical series and United States population level burden estimate. J Urol 2015;193:30-5.

13. Kang HW, Seo SP, Kim WT, Yun SJ, Lee SC, Kim WJ, et al. Impact of young age at diagnosis on survival in patients with surgically treated renal cell carcinoma: a multicenter study. J Korean Med Sci 2016;31:1976-82.

14. Edge SB, Compton CC. The American Joint Committee on Cancer: the 7th edition of the AJCC cancer staging manual and the future of TNM. Ann Surg Oncol 2010;17:1471-4.

15. Fuhrman SA, Lasky LC, Limas C. Prognostic significance of morphologic parameters in renal cell carcinoma. Am J Surg Pathol 1982;6:655-63.

16. Dindo D, Demartines N, Clavien PA. Classification of surgical complications: a new proposal with evaluation in a cohort of 6336 patients and results of a survey. Ann Surg 2004;240:20513.

17. King SC, Pollack LA, Li J, King JB, Master VA. Continued increase in incidence of renal cell carcinoma, especially in young patients and high grade disease: United States 2001 to 2010. J Urol 2014;191:1665-70.

18. Ferlay J, Soerjomataram I, Dikshit R, Eser S, Mathers C, Rebelo $\mathrm{M}$, et al. Cancer incidence and mortality worldwide: sources, methods and major patterns in GLOBOCAN 2012. Int J Cancer 2015;136:E359-86.

19. Joung JY, Lim J, Oh CM, Jung KW, Cho H, Kim SH, et al. Current trends in the incidence and survival rate of urological cancers in Korea. Cancer Res Treat 2017;49:607-15.

20. Dulabon LM, Lowrance WT, Russo P, Huang WC. Trends in renal tumor surgery delivery within the United States. Cancer 2010;116:2316-21.

21. Golombos DM, Chughtai B, Trinh QD, Thomas D, Mao J, Te A, et al. Minimally invasive vs open nephrectomy in the modern era: does approach matter? World J Urol 2017;35:1557-68.

22. Banegas MP, Harlan LC, Mann B, Yabroff KR. Toward greater adoption of minimally invasive and nephron-sparing surgical techniques for renal cell cancer in the United States. Urol Oncol 2016;34:433.e9-17.

23. Ghani KR, Sukumar S, Sammon JD, Rogers CG, Trinh QD, Menon M. Practice patterns and outcomes of open and minimally invasive partial nephrectomy since the introduction of robotic partial nephrectomy: results from the nationwide inpatient sample. J Urol 2014;191:907-12.

24. Pignot G, Méjean A, Bernhard JC, Bigot P, Timsit MO, Ferriere JM, et al.; CCAFU members. The use of partial nephrectomy: results from a contemporary national prospective multicenter study. World J Urol 2015;33:33-40.

25. Thompson RH, Kaag M, Vickers A, Kundu S, Bernstein M, Lowrance W, et al. Contemporary use of partial nephrectomy at a tertiary care center in the United States. J Urol 2009;181:993-7.

26. Jeon HG, Lee SR, Kim KH, Oh YT, Cho NH, Rha KH, et al. Benign lesions after partial nephrectomy for presumed renal cell carcinoma in masses $4 \mathrm{~cm}$ or less: prevalence and predictors in Korean patients. Urology 2010;76:574-9.

27. Corcoran AT, Russo P, Lowrance WT, Asnis-Alibozek A, Libertino JA, Pryma DA, et al. A review of contemporary data on surgically resected renal masses--benign or malignant? Urology 2013;81:707-13.

28. Leibovich BC, Lohse CM, Crispen PL, Boorjian SA, Thompson $\mathrm{RH}$, Blute $\mathrm{ML}$, et al. Histological subtype is an independent predictor of outcome for patients with renal cell carcinoma. J Urol 2010;183:1309-15. 
29. Patard JJ, Leray E, Rioux-Leclercq N, Cindolo L, Ficarra V, Zisman A, et al. Prognostic value of histologic subtypes in renal cell carcinoma: a multicenter experience. J Clin Oncol 2005;23:2763-71.
30. Karakiewicz PI, Briganti A, Chun FK, Trinh QD, Perrotte P, Ficarra V, et al. Multi-institutional validation of a new renal cancer-specific survival nomogram. J Clin Oncol 2007;25:1316-22. 